\title{
Pyruvate Protection against Endothelial Cytotoxicity Induced by Blockade of Glucose Uptake
}

\author{
Se-Jin Chung, Se-Hee Lee, Yong-Jin Lee, Hyoung-Sook Park ${ }^{\dagger}$, Rolf Bünger ${ }^{\dagger}$ and Young-Hee Kang* \\ Division of Life Sciences and Silver Biotechnology Research Center, Hallym University, Chuncheon 200-702, Korea \\ 'Department of Environmental Engineering, Hanseo University, Seosan 356-706, Korea \\ ${ }^{\ddagger}$ Physiology and Molecular/Cell Biology, Uniformed Services University of Health Sciences, Bethesda, Maryland 20814, USA
}

Received 23 June 2003, Accepted 29 July 2003

\begin{abstract}
We have previously demonstrated that the redox reactant pyruvate prevents apoptosis in the oxidant model of bovine pulmonary artery endothelial cells (BPAEC), and that the anti-apoptotic mechanism of pyruvate is mediated in part via the mitochondrial matrix compartment. However, cytosolic mechanisms for the cytoprotective feature of pyruvate remain to be elucidated. This study investigated the pyruvate protection against endothelial cytotoxicity when the glycolysis inhibitor 2-deoxy-D-glucose (2DG) was applied to BPAEC. Millimolar 2DG blocked the cellular glucose uptake in a concentration- and time-dependent manner with $>85 \%$ inhibition at $\geq 5 \mathrm{mM}$ within $24 \mathrm{~h}$. The addition of 2DG evoked BPAEC cytotoxicity with a substantial increase in lipid peroxidation and a marked decrease in intracellular total glutathione. Exogenous pyruvate partially prevented the 2DG-induced cell damage with increasing viability of BPAEC by $25-30 \%$, and the total glutathione was also modestly increased. In contrast, $10 \mathrm{mM}$ L-lactate, as a cytosolic reductant, had no effect on the cytotoxicity and lipid peroxidation that are evoked by 2DG. These results suggest that $2 D G$ toxicity may be a consequence of the diminished potential of glutathione antioxidant, which was partially restored by exogenous pyruvate but not L-lactate. Therefore, pyruvate qualifies as a cytoprotective agent for strategies that attenuate the metabolic dysfunction of the endothelium, and cellular glucose oxidation is required for the functioning of the cytosolic glutathione/NADPH redox system.
\end{abstract}

Keywords: 2-Deoxy-D-glucose, Endothelial cells, Glutathione, L-Lactate, Lipid peroxidation, Pyruvate

\footnotetext{
*To whom correspondence should be addressed.

Tel: 82-33-240-1475; Fax: 82-33-254-1475

E-mail: yhkang@hallym.ac.kr
}

\section{Introduction}

Pyruvate as a key anaplerotic redox reactant can be cardioprotective during hypoxia, re-oxygenation, and cardioplegia, as well as during hemorrhagic shock (Zhou et al., 1995; Mongan et al., 1999; Dobsak et al., 1999). Cardiomyocytes tolerate supraphysiological concentrations of nontoxic pyruvate (Scholz et al., 1995; Mallet and Sun, 1999), stabilizing the ATP pool and raising the cytoplasmic redox and phosphorylation potential (Mallet and Sun, 1999). In addition, pyruvate has the ability to scavenge peroxides and metal ions in cell free systems (Herz et al., 1997; Kang et al., 2001; Kang et al., 2002). We demonstrated that millimolar pyruvate prevents hydrogen peroxide $\left(\mathrm{H}_{2} \mathrm{O}_{2}\right)$-induced apoptosis in cultured thymocytes and endothelial cells (Ramakrishnan et al., 1998; Kang et al., 2001). Pyruvate appears to disable the mitochondrial death pathway via metabolic improvement in the mitochondrial matrix (Halestrap et al., 1998; Mallet and Sun, 1999; Kang et al., 2001). However, the exact cellular mechanisms for this antiapoptotic feature of pyruvate are not firmly defined. Other possible mechanisms for the cellular antioxidant defenses of pyruvate may relate to the pentose phosphate pathway linkedNADPH/glutathione system (Tejero-Taldo et al., 1999) and the lactate dehydrogenase-controlled cytoplasmic NADH/ $\mathrm{NAD}^{+}$system (Mohazzab et al., 1997; Martin et al., 1998). The latter has been implicated in the production of the reactive oxygen species (ROS) via an NADH oxidase that catalyzes the single electron transfer from NADH to molecular oxygen (Mohazzab et al., 1997; Bassenge et al., 2000).

We examined the cytotoxicity of 2-deoxy-D-glucose (2DG), a non-metabolized glucose analogue that is known to inhibit the glycolytic pathway by competing with glucose for cellular transport (Brown, 1962; Abbink et al., 2001), in bovine pulmonary artery endothelial cells (BPAEC). We hypothesized that pyruvate per se can improve cellular antioxidant defenses through the stabilization of subcellular 
energetics. To test this hypothesis, BPAEC was treated with millimolar pyruvate in the presence of 2DG. The cytosolic reductant L-lactate was used for comparisons. Measuring the cell viability, lipid peroxidation, and total glutathione level determined the cytotoxicity after 2DG stress in the vascular endothelium.

\section{Materials and Methods}

Culture of endothelial cells and in vitro 2DG injury model BPEAC were obtained from the American Type Culture Collection (Rockville, USA). The cells were plated in a M199 medium (+1 g/l glucose) that was supplemented with $25 \mathrm{mM}$ HEPES and $10 \%$ fetal bovine serum and grown in air for $24 \mathrm{~h}$ at $37^{\circ} \mathrm{C}$ under $5 \% \mathrm{CO}_{2}$. To examine the time course and dose-responses of 2DG to cell viability, the cells were incubated for $24 \mathrm{~h}$ with $1-15 \mathrm{mM} 2 \mathrm{DG}$ (Sigma, St. Louis, USA). The cells were also incubated for $24 \mathrm{~h}$ with $10 \mathrm{mM}$ pyruvate or L-lactate in the presence of various concentrations of $2 \mathrm{DG}$ in order to determine whether pyruvate may improve the cellular response that is impaired by 2DG.

To determine whether 2DG blocks the cellular glucose uptake, medium L-lactate was enzymatically measured (Kontron Inc, Tegimenta, Switzerland) at $\lambda=340 \mathrm{~nm}$, essentially according to Bergmeyer (Bergmeyer, 1974).

Cell viability At the end of the 24 h-incubation period, a 3-(4,5dimetylthiazol-yl)-diphenyl tetrazolium bromide (MTT) assay was performed to determine the growth rate and quantitate cellular viability (Denizot and Lang, 1986). Absorbance of the purple formazan product was measured colorimetrically at $\lambda=570 \mathrm{~nm}$ with background subtraction using $\lambda=690 \mathrm{~nm}$.

Lipid peroxidation To examine whether 2DG causes lipid peroxidation, thiobarbituric acid reactive substances (TBARS) were measured in BPAEC that was exposed to 2DG. The incubation medium was subjected to the thiobarbituric acid assay. The absorbance of the medium was determined at $\lambda=535 \mathrm{~nm}$, according to the previous method with a minor modification (Buege and Aust, 1978). The cell protein contents were determined by the Lowry method (Lowry et al., 1951). TBARS were expressed as nmol malondialdehyde (MDA) as a lipid peroxidation product per mg protein.

Activation of xanthine oxidase By competing with glucose for the cellular membrane transport, the glycolytic blockade of 2DG may decrease the ATP pool (Abbink et al., 2001). Thus, it was speculated that 2DG could produce ROS via the activation of xanthine oxidase catalyzing hypoxanthine/xanthine to uric acid, a breakdown end product of ATP (Becker et al., 1985). To determine whether xanthine oxidase is activated by $2 \mathrm{DG}$, medium uric acid was enzymatically measured at $\lambda=293 \mathrm{~nm}$ using uricase degrading uric acid to allantoin (according to Bergmeyer); at this wavelength 2DG did not interfere with the absorbance.

Cellular glutathione level Total glutathione was examined using the previous 5,5-dithio-bis(2-nitro-benzoic acid) assay with a minor modification (Baker et al., 1990). After experimental protocols, the cells were washed with PBS and extracted with ice-cold 2.25\% (w/ v) 5-sulfosalicylic acid. The cell extracts were centrifuged at $12,000 \times g$ for $20 \mathrm{~min}$ at $4^{\circ} \mathrm{C}$. The supernatant was used for the subsequent determination of total glutathione, whereas the pellet was dissolved in a lysis buffer of $0.1 \mathrm{M} \mathrm{NaOH}(+0.1 \%$ SDS $)$ for the determination of cell protein content. The total glutathione levels in the acid-soluble extracts were determined by an enzymatic recycling assay with a $100 \mathrm{mM}$ sodium phosphate buffer ( $\mathrm{pH}$ 7.4). The buffer contained $0.75 \mathrm{mM}$ 5,5-dithio-bis(2-nitro-benzoic acid), $5.5 \mathrm{mM}$ EDTA, and $1 \mathrm{U} / \mathrm{mL}$ glutathione reductase, as well as 0.26 $\mathrm{mM}$ NADPH. The linear changes in absorbance at $405 \mathrm{~nm}$ were recorded for $6 \mathrm{~min}$. Parallel measurements of the glutathione standards were performed to quantify the total glutathione levels that were expressed as nmol per $10^{6}$ cells.

Data analysis The results are presented as mean $\pm \mathrm{SEM}$. Statistical analyses were conducted using the Statistical Analysis Systems statistical software package version 6.12 (SAS Institute Inc., Cary, USA). A one-way analysis of the variance was used to determine the differences between the effects of the two treatment groups. The differences among the treatment groups were analyzed with Duncans multiple range test and were considered significant. Statistical significance was set at $\mathrm{P}<0.05$.

\section{Results}

Blockade of glucose uptake by 2DG To confirm that 2DG competitively inhibits the cellular uptake of glucose under the present protocols, medium L-lactate was measured. Compared to that observed in 2DG-free incubations (Fig. 1), 2DG significantly blocked the L-lactate release in a concentrationdependent manner after $12 \mathrm{~h}$ with $>85 \%$ inhibition at $\geq 5 \mathrm{mM}$

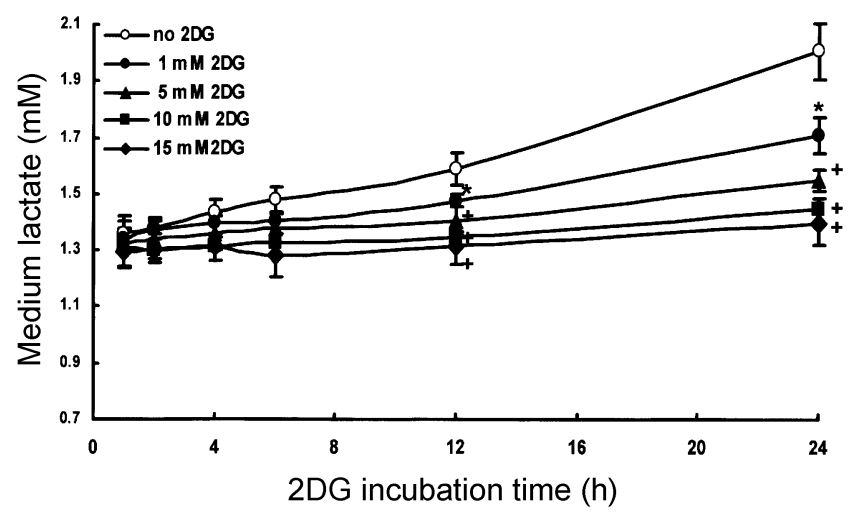

Fig. 1. Blockade of glucose uptake by 2-deoxy-D-glucose (2DG) in bovine pulmonary artery endothelial cells over $24 \mathrm{~h}$. The direct effect of 2DG on L-lactate release was determined. Control cells were also incubated with 2DG-free M199 media. Medium L-lactate was enzymatically measured. Data are presented as mean \pm SEM of 5 separate incubations. $* \mathrm{P}<0.05$, relative to no $2 \mathrm{DG}$ controls. ${ }^{+} \mathrm{P}<0.05$, relative to both no $2 \mathrm{DG}$ controls and $1 \mathrm{mM} 2 \mathrm{DG}$. 


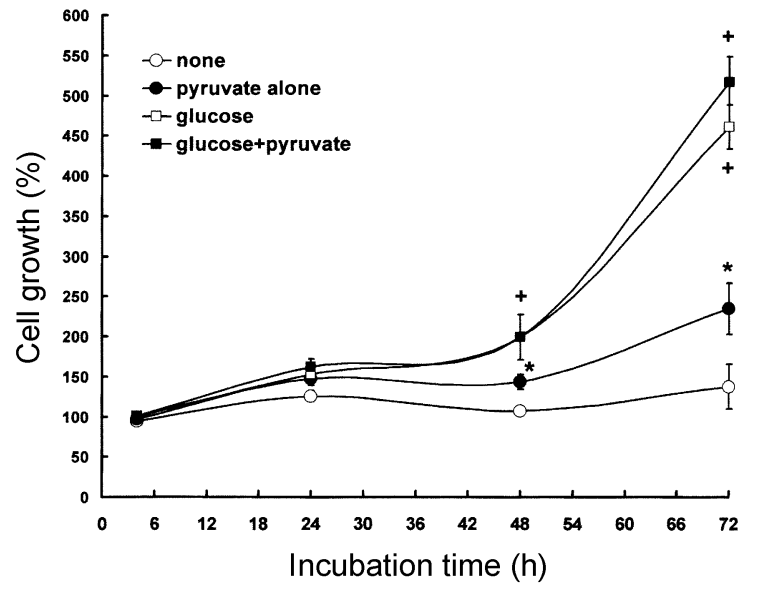

Fig. 2. Typical time course response of the bovine pulmonary artery endothelial cell growth under different conditions of energy supply. Cells were incubated in M199 media containing 1 $\mathrm{g} / \mathrm{l}$ glucose in the absence and presence of $10 \mathrm{mM}$ pyruvate for $72 \mathrm{~h}$. Cells were also grown in M199 media with no substrate (none). Data (mean \pm SEM, $n=4$ ) are expressed as percent cell growth relative to none (cell growth $=100 \%$ ). $* \mathrm{P}<0.05$, relative to none. ${ }^{+} \mathrm{P}<0.05$, relative to pyruvate alone.

within $24 \mathrm{~h}$. This indicates that 2DG almost completely inhibited the glucose uptake and glycolysis of BPAEC.

2DG toxicity BPAEC did not grow in the glucose-free media, while cells grew rapidly after $48 \mathrm{~h}$ in the glucosecontaining media, which indicates that glucose is essential for cell growth (Fig. 2). The addition of $10 \mathrm{mM}$ pyruvate to the glucose-free media modestly increased cell growth. Thus, pyruvate per se in glucose-free media is a good energy source that doubles cell growth.

Figure 3A shows that millimolar 2DG decreased cell viability in a concentration- and incubation time-dependent manner with a rapid decline within $6 \mathrm{~h}$, and thereafter nearlinearly. The killing was up to $\approx 30 \%$ at $4 \mathrm{~h}$ at $5 \mathrm{mM} 2 \mathrm{DG}$. The decreased viability was possibly due to the inhibition of glycolysis by 2DG, as shown in the lactate release data of Fig. 1. The blockade of the glucose uptake by 2DG increased the TBARS formation in concentration and incubation time dependent manner (Fig. 3B). At $\geq 5$ mM, TBARS significantly accumulated in the medium over 6-24 h.

Cytoprotection of pyruvate against the toxicity of 2DG Figure 4A shows the cytoprotective effect of exogenous pyruvate against 2DG toxicity. The $24 \mathrm{~h}$-incubation with 2DG decreased the cell viability concentration-dependently with killing up to $\approx 50 \%$ at $15 \mathrm{mM}$. Pyruvate at $10 \mathrm{mM}$ inhibited the toxicity of $2 \mathrm{DG}$ at all of the tested concentrations, with a small but still significant increase in the cell viability by 5$10 \%$. In contrast, equimolar L-lactate had no protective effect on cell injury that was evoked by $10 \mathrm{mM} 2 \mathrm{DG}$ (Fig. 4B).

Lipid peroxidation was induced by $2 \mathrm{DG}$ within $24 \mathrm{~h}$, as
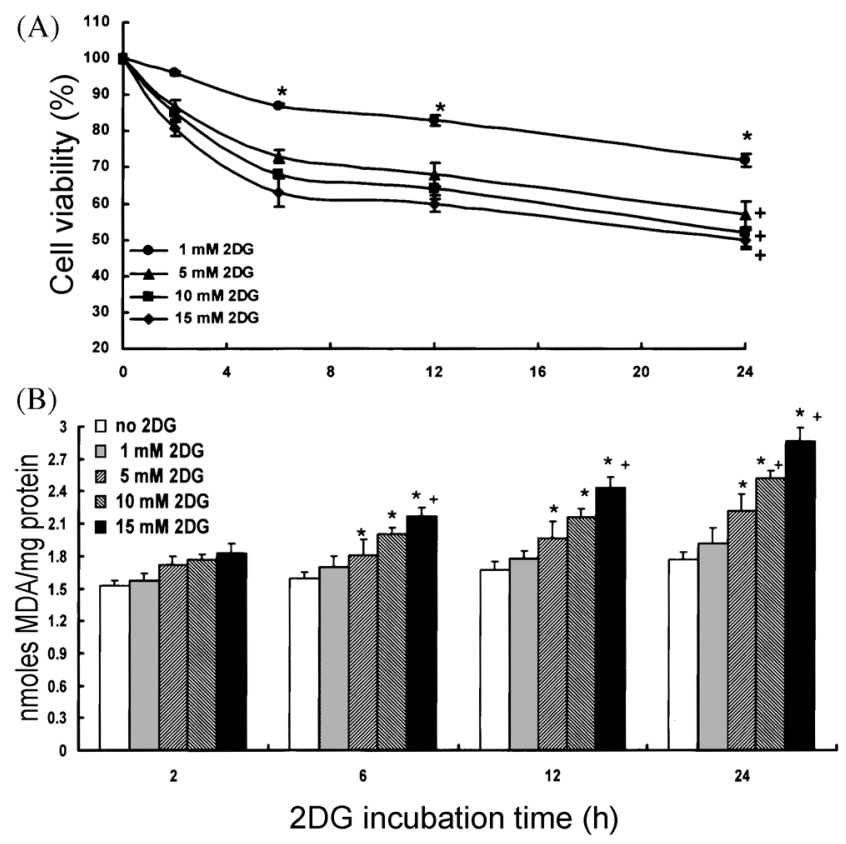

Fig. 3. Dose-response relationships between 2-deoxy-D-glucose (2DG) and bovine pulmonary artery endothelial cell viability (panel A). Cells were treated with various concentrations of 2DG over $24 \mathrm{~h}$. Cell viability was assessed by MTT test. Data (mean $\pm \mathrm{SEM}, \mathrm{n}=5$ ) are expressed as percent cell survival relative to 2DG-free controls. $* \mathrm{P}<0.05$, relative to $2 \mathrm{DG}$-free controls (viability $=100 \%) .{ }^{+} \mathrm{P}<0.05$, relative to cell viability with $1 \mathrm{mM}$ 2DG after $24 \mathrm{~h}$. Concentration-response in TBARS formation (panel B). TBARS data (mean \pm SEM, $n=5$ ) was expressed as nmol MDA/mg protein. $* \mathrm{P}<0.05$, relative to $2 \mathrm{DG}$-free incubation (no $2 \mathrm{DG}$ ) at respective incubation time. ${ }^{+} \mathrm{P}<0.05$, relative to $2 \mathrm{~h}-$ incubation at respective concentration of $2 \mathrm{DG}$.

shown in the TBARS data of Fig. 3B. Pyruvate, but not Llactate, significantly lessened the TBARS formation in the 2DG-exposed cells (Fig. 5A). In addition, pyruvate inhibited the $\mathrm{H}_{2} \mathrm{O}_{2}$ toxicity in the 2DG-exposed cells (data not shown). However, the substantial peroxidative injury that is induced by 2DG may be responsible for the incomplete pyruvate cytoprotection. Figure 5B depicts the dependence of endothelial cell viability on lipid peroxidation, measured as TBARS formation. There was a highly significant inverse linear correlation $\left(\mathrm{R}^{2}=0.9257\right)$ between the degree of lipid peroxidation and endothelial cell viability, indicating that the cytotoxicity of 2DG was at least partially mediated via lipid peroxidation.

Peroxidative injury by 2DG It has been demonstrated that xanthine oxidase is responsible for hypoxia/re-oxygenationinduced ROS formation and renal epithelial cell injury (Greene and Paller, 1992). One can assume possible mechanisms for the 2DG-induced endothelial toxicity. Possibly, 2DG produces ROS during the activation of xanthine oxidase, perhaps due to an accumulation of the ATP breakdown products, hypoxanthine and xanthine. 

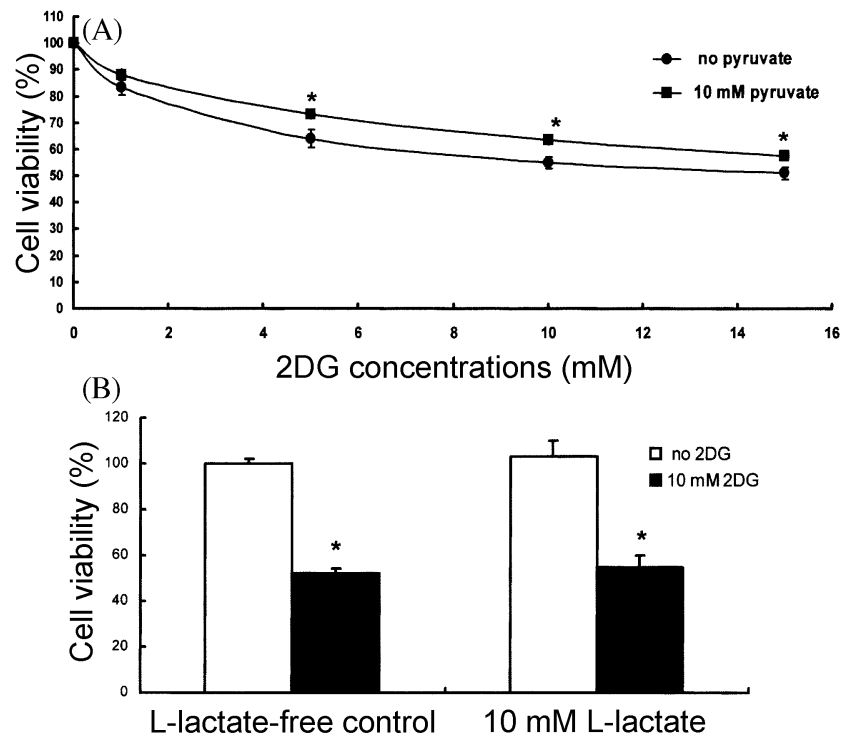

Fig. 4. Effects of pyruvate on viability of 2-deoxy-D-glucose (2DG)-treated bovine pulmonary artery endothelial cells (panel A). Cells were incubated with and without $10 \mathrm{mM}$ pyruvate in the presence of various concentrations of 2DG for $15 \mathrm{~h}$. After a $15 \mathrm{~h}$ incubation, the cell viability was assessed. Data (mean \pm SEM, $\mathrm{n}=6$ ) are expressed as percent cell survival of 2DG-untreated controls (viability $=100 \%$ ). $* \mathrm{P}<0.05$, relative to incubations at respective concentration of $2 \mathrm{DG}$. In panel $\mathrm{B}$, cells were incubated with and without $10 \mathrm{mM}$ L-lactate in the absence and presence of $10 \mathrm{mM} 2 \mathrm{DG}$ for $15 \mathrm{~h}$. Data (mean $\pm \mathrm{SEM}, \mathrm{n}=5$ ) are expressed as percent cell survival of $2 \mathrm{DG}$-untreated controls. ${ }^{*} \mathrm{P}<0.05$, relative to respective 2DG-free incubation (no 2DG).

Hypoxanthine and xanthine appeared to modestly accumulate with incubation times over $24 \mathrm{~h}$. However, there was no significant increase in their accumulation in 2DG-treated BPAEC (Fig. 6), suggesting that the 2DG-induced peroxidative injury was probably not due to the ROS formation via an activation of xanthine oxidase.

Blocking the glucose uptake, and in turn glycolysis by 2DG, may modulate the subcellular NADH/NAD ${ }^{+}$system, which has been implicated in the production of ROS via $\mathrm{NADH}$ oxidase activity that catalyzes the single electron transfer from NADH to molecular oxygen (Mohazzab, H. et al., 1997; Bassenge et al., 2000). Such a mechanism can be speculated in the 2DG-induced peroxidative injury. As shown, exogenous NADH measurably potentiated the 2DG toxicity, and pyruvate did not protect against 2DG plus NADHinduced cellular demise (unpublished data).

2DG toxicity and intracellular total glutathione level Applying $10 \mathrm{mM} 2 \mathrm{DG}$ to BPAEC caused a $\approx 40 \%$ decline in the intracellular total glutathione (Table 1, row 3), which could be due to the possible inhibition of the pentose phosphate flux that resulted from the cellular uptake and utilization of glucose. However, pyruvate produced a small but significant increase in the total glutathione level (row 4).
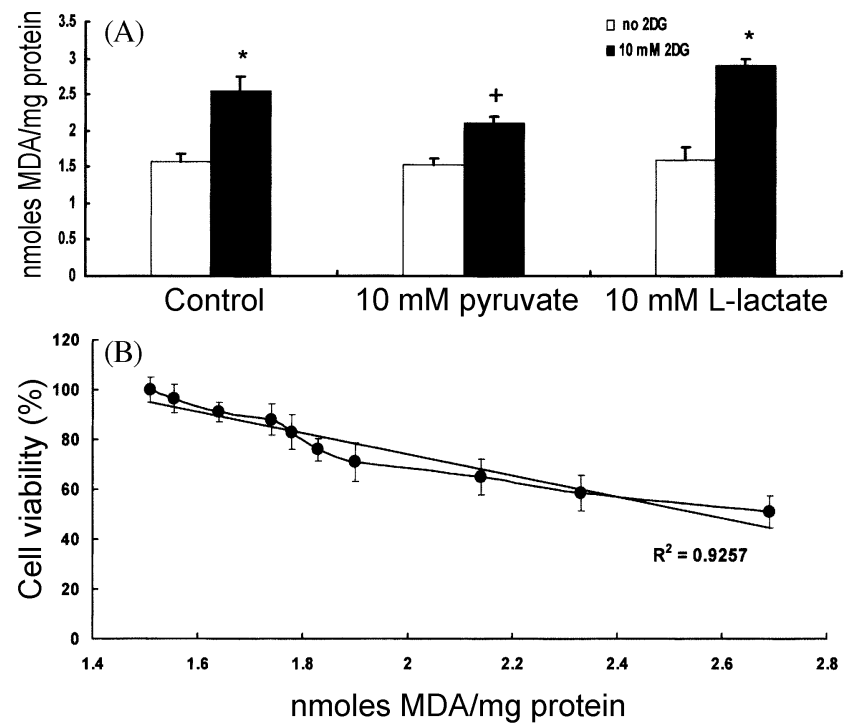

Fig. 5. Lipid peroxidation in 2-deoxy-D-glucose (2DG)-treated cells (panel A). Bovine pulmonary artery endothelial cells were incubated with and without $10 \mathrm{mM}$ pyruvate or L-lactate in the absence and presence of $10 \mathrm{mM}$ 2DG. After a 15 h-incubation, TBARS data (mean $\pm \mathrm{SEM}, \mathrm{n}=6$ ) are expressed as nmol MDA/ mg protein. $* \mathrm{P}<0.05$, relative to respective $2 \mathrm{DG}$-free controls (no $2 \mathrm{DG}$ ). $+\mathrm{P}<0.05$, relative to $10 \mathrm{mM} 2 \mathrm{DG}$-controls. Panel B shows a direct relationship between cell viability and TBARS in 2DGtreated BPAEC. Endothelial cells were incubated with various concentrations of 2DG over $24 \mathrm{~h}$. TBARS was expressed as nmol $\mathrm{MDA} / \mathrm{mg}$ protein, and cell viability was expressed as percent viability of 2DG-free incubations.

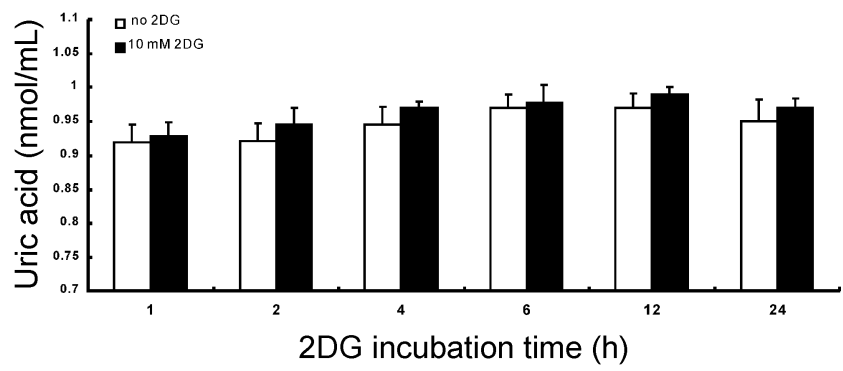

Fig. 6. Endothelial uric acid production over $24 \mathrm{~h}$ with and without $10 \mathrm{mM}$ 2-deoxy-D-glucose (2DG). Bovine pulmonary artery endothelial cells were incubated with $10 \mathrm{mM} 2 \mathrm{DG}$ over $24 \mathrm{~h}$. All data are presented as mean \pm SEM of 5 separate incubations.

\section{Discussion}

There are four major observations from this study: (1) Millimolar 2DG reduced cell viability in a concentration and incubation time dependent manner with killing up to $\approx 45 \%$ within $24 \mathrm{~h}$ at $15 \mathrm{mM}$. The decreased cell viability by $2 \mathrm{DG}$ might be a result of the virtual de-energization by blocking the endothelial glucose uptake. (2) The 2DG-induced cell injury appeared to be due to lipid peroxidation and not ROS 
Table 1. Effect of exogenous pyruvate on intracellular total glutathione of 2DG-exposed endothelial cells

\begin{tabular}{cc}
\hline conditions & $\begin{array}{c}\text { total glutathione } \\
\left(\mathrm{nmol} / 10^{6} \text { cells }\right)\end{array}$ \\
\hline control & $13.39 \pm 0.65^{\mathrm{a}}$ \\
pyruvate & $14.58 \pm 1.07^{\mathrm{a}}$ \\
2DG & $7.74 \pm 0.34^{\mathrm{b}}$ \\
2DG plus pyruvate & $9.25 \pm 0.57^{\mathrm{c}}$ \\
\hline
\end{tabular}

Bovine pulmonary artery endothelial cells were cultured with and without $10 \mathrm{mM}$ pyruvate in the absence and presence of $10 \mathrm{mM}$ 2-deoxy-D-glucose (2DG). Control cultures were conducted with glucose-only-containing media. After a 24 h-incubation, intracellular total glutathione was extracted and spectrophotometrically measured. Data are mean \pm SEM from 4 separate incubations. Values with different superscripts are significantly different at $\mathrm{P}$ $<0.05$.

formation via the possible activation of xanthine oxidase. (3) Exogenous pyruvate, but not L-lactate, ameliorated cytotoxicity and TBARS formation that was induced by 2DG. (4) Applying 2DG to BPAEC caused a marked depletion of intracellular total glutathione, which was probably caused by the impaired pentose phosphate flux. Pyruvate, however, improved the total glutathione level that was reduced by 2DG. These observations make it likely that the pyruvate per se can improve cellular antioxidant defenses through the stabilization of subcellular energetics.

We have demonstrated that BPAEC, when subjected to submillimolar $\mathrm{H}_{2} \mathrm{O}_{2}$, is lethal and millimolar pyruvate almost completely inhibits $\mathrm{H}_{2} \mathrm{O}_{2}$-induced toxicity. Also, the cytoprotective mechanism of pyruvate is partly mediated via the mitochondrial death pathway (Kang et al., 2001). The current study elucidates whether pyruvate per se can protect the endothelium without functional availability and cellular oxidation of glucose. 2DG has been known to compete with glucose on the cell membrane, and hence inhibit glycolysis and ATP production (Brown, 1962). Our data in Fig. 1 show that the 2DG incubation markedly decreased the endothelial L-lactate release, which was consistent with the selective blockade of the glucose uptake on the plasma membrane. Accordingly, the 2DG inhibition of glycolysis reflects the ATP depletion, resulting in endothelial de-energization. It has been reported that $2 \mathrm{DG}$ results in virtually instantaneous deenergization during ischemic reperfusion (Abbink et al., 2001). Thus, it is assumed that the $2 \mathrm{DG}$ toxicity was a consequence of endothelial de-energization, indicating that the glucose oxidation was essential for normal cell growth.

Millimolar 2DG induced a concentration- and timedependent cytotoxicity. Cell injury by 2DG also appeared to result from the membrane lipid peroxidation, as shown by the cell viability and TBARS data in Fig. 3. Exogenous pyruvate, but not exogenous L-lactate, diminished the lipid peroxidation of 2DG-exposed cells. In addition, the membrane lipid peroxidation was suggested as an important factor in cell damage that resulted from oxidative stress (Nishida et al., 1982; Carini et al., 1992; Rice-Evans and Burdon, 1993; Kamat et al., 2000; Park et al., 2001; Yoon et al., 2002). From these reports, we can speculate that lipid peroxidation in the presence of 2DG may result from 2DG-induced generation of ROS. Assumedly, there are at least two mechanisms of 2DGstimulated production of ROS and endothelial lipid peroxidation: (1) Xanthine generates ROS in the posthypoxic injury of renal epithelial cells (Greene and Paller, 1992). In the present study, 2DG-induced de-energization did not accompany significant activation of endothelial xanthine oxidase. Accordingly, the 2DG-induced cell injury was unlikely due to the xanthine oxidase-stimulated production of ROS. (2) Cytosolic NADH accumulation causes the reductive release of complex ferritin iron producing free $\mathrm{Fe}^{2+}$, the catalyst of the hydroxyl radicals in the Fenton reaction (Voogd et al., 1994; Park et al., 2001). NADH oxidase generates ROS, providing free electrons from $\mathrm{NADH}+\mathrm{H}^{+}$in the cytosol (Mohazzab, H. et al., 1997; Ellis et al., 1998). Blocking glucose uptake by 2DG may increase the intracellular NADH/ $\mathrm{NAD}^{+}$ratio, which in turn activates NADH oxidase. Although we did not measure cytosolic NADH, we found that 2DG did not alter the medium L-lactate/pyruvate ratio, indicating an increase in cytosolic NADH (data not shown). Therefore, the activation of $\mathrm{NADH}$ oxidase may not be involved in generating ROS. Possible sources of ROS that are generated by 2DG were not discovered.

Under our glucose-free conditions, exogenous pyruvate doubled cell growth within $72 \mathrm{~h}$. Under 2DG incubation conditions, pyruvate inhibited the 2DG toxicity by $5-10 \%$. This incomplete cytoprotection of pyruvate against 2DG injury appeared to be due to lipid peroxidation. On the other hand, L-lactate did not improve 2DG toxicity. One can predict that L-lactate results in a massive accumulation of a cellular reducing equivalent of NADH with an increased proton load. Consequently, excess L-lactate in the presence of 2DG could have facilitated the formation of ROS, rendering endothelial cells more vulnerable to a given oxidant stress (Mohazzab, $\mathrm{H}$. et al., 1997).

The pentose phosphate pathway-linked NADPH supply and activation of the glutathione redox cycle will be clearly inhibited due to the blockade of the glucose uptake by 2DG in the present cell system. Glucose 6-phosphate is the substrate of the glucose 6-phosphate dehydrogenase, a rate-limiting enzyme of the pentose phosphate pathway. As expected, the addition of 2DG to BPAEC caused a marked decline in total glutathione, which could be due to the inhibition of the pentose phosphate pathway. In addition, the depletion of cytosolic glutathione in the presence of 2DG may result in ROS accumulation and lipid peroxidation. The glutathione/ NADPH system defends cells against oxidative stress at the single cell level and in tissues (Kehrer and Lund, 1994; Park et al., 2001). Oxidative damage is accompanied by the production of ROS and impairment of anti-oxidative defense systems following cerebral glutathione depletion (Gupta et al., 
2000). Pyruvate increases the redox potential of cytosolic glutathione and the NADPH reducing equivalent, possibly via an anaplerotically metabolic regulation of cytosolic phosphofructokinase (Tejero-Taldo et al., 1999). In addition, pyruvate ameliorates high glucose toxicity through the activation of the pentose phosphate pathway and glutathione redox cycle in endothelial cells (Kashiwagi et al., 1997). Millimolar pyruvate significantly improved the glutathione redox potential, but incompletely in the 2DG-treated endothelial cells (Table 1). Therefore, the partial cytoprotection of pyruvate against the 2DG toxicity may be explained by its incomplete restoration of intracellular total glutathione.

In summary, millimolar $2 \mathrm{DG}$ inhibited $\geq 85 \%$ glucose uptake and induced BPAEC injury. Inhibition of glycolysis by 2DG resulted in the depletion of the intracellular glutathione, which in turn most likely triggered ROS production. 2DG evoked lipid peroxidation that may be, at least in part, responsible for the BPAEC injury. Exogenous pyruvate, but not L-lactate, ameliorated cytotoxicity and TBARS formation that are induced by 2DG, which might be a consequence of a small but significant increase in intracellular total glutathione. Therefore, the pyruvate per se can improve cellular antioxidant defenses through the stabilization of subcellular energetics. Pyruvate activation of the lactate dehydrogenasecontrolled cytoplasmic NADH/NAD ${ }^{+}$redox system and/or pyruvate inhibition of NADH oxidases-stimulated ROS production may be involved in the pyruvate cytoprotection.

Acknowledgments This research was supported by a grant (R12-2001-007202-0) from the Korea Science \& Engineering through the Silver Biotechnology Research Center at Hallym University and by the research grant from Hallym University, Korea.

\section{References}

Abbink, E. J., Tack, C. J. and Smits, P. (2001) Vascular effects of metabolic inhibition by 2-deoxy-D-glucose in human. $J$. Cardiovas. Pharmacol. 37, 94-100.

Baker, M. A., Cerniglia, G. J. and Zaman, A. (1990) Microtiter plate assay for the measurement of glutathione and glutathione disulfide in large numbers of biological samples. Anal. Biochem. 190, 360-365.

Bassenge, E., Sommer, O., Schwemmer, M. and Bunger, R. (2000) Antioxidant pyruvate inhibits cardiac formation of reactive oxygen species through changes in redox state. Am. J. Physiol. 279, H2431-H2438.

Becker, B. F., Gerlach, E. and Nees, S. (1985) The vascular endothelium: A survey of some newly evolving biochemical and physiological features. Basic Res. Cardiol. 80, 459-474.

Bergmeyer, H. U. (1974) Methods of Enzymatic Analysis, 2nd ed., Verlag Chemie Weinheim, Academic Press, New York, USA.

Brown, J. (1962) Effects of 2-deoxyglucose on carbohydrate metabolism: review of the literature and studies in the rat.
Metabolism 11, 1098-1111.

Buege, J. A. and Aust, S. D. (1978) Microsomal lipid peroxidation. Methods enzymol. 52, 302-310.

Carini, R., Parola, M., Dianzani, M. U. and Albano, E. (1992) Mitochondrial damage and its role in causing hepatocyte injury during stimulation of lipid peroxidation by iron nitriloacetate. Arch. Biochem. Biophys. 297, 110-118.

Denizot, F. and Lang, R. (1986) Rapid colorimetric assay for cell growth and survival. Modification to the tetrazolium dye procedure giving improved sensitivity and reliability. $J$. Immunol. Methods 89, 271-277.

Dobsak, P., Courderot-Masuyer, C., Zeller, M., Vergely, C., Laubriet Assem, M., Eicher, J. C., Teyssier, J. R., Wolf, J. E. and Rochette, L. (1999) Antioxidative properties of pyruvate and protection of the ischemic rat heart during cardioplegia. $J$. Cardiovasc. Pharmacol. 34, 651-659.

Ellis, E. A., Grant, M. B., Murray, F. T., Wachowski, M. B., Guberski, D. L., Kubilis, P. S. and Lutty, G. A. (1998) Increased NADH oxidase activity in the retina of the BBZ/Wor diabetic rat. Free Radic. Biol. Med. 24, 111-120.

Greene, E. L. and Paller, M. S. (1992) Xanthine oxidase produces $\mathrm{O}_{2}^{-}$in posthypoxic injury of renal epithelial cells. Am. J. Physiol. 263, F251-F255.

Gupta, A., Gupta, A., Datta, M. and Shukla, G. S. (2000) Cerebral antioxidant status and free radical generation following glutathione depletion and subsequent recovery. Mol. Cell. Biochem. 209, 55-61.

Halestrap, A. P., Kerr, P. M., Javadov, S. and Woodfield, K. Y. (1998) Elucidating the molecular mechanism of the permeability transition pore and its role in reperfusion injury of the heart. Biochim. Biophys. Acta 1366, 79-94.

Herz, H., Blake, D. R. and Grootveld, M. (1997) Multicomponent investigations of the hydrogen peroxide- and hydroxyl radical scavenging antioxidant capacities of biofluids: the roles of endogenous pyruvate and lactate. Free Radic. Res. 26, 19-35.

Kamat, J. P., Boloor, K. K. and Devasagayam, T. P. (2000) Chlorophyllin as an effective antioxidant against membrane damage in vitro and ex vivo. Biochim. Biophys. Acta 1487, 113-127.

Kang, Y. H., Chung, S. J., Park, J. H. Y., Kang, I. J. and Bunger, R. (2001) Intramitochondrial pyruvate attenuates hydrogen peroxide-induced apoptosis in bovine pulmonary artery endothelium. Mol. Cell. Biochem. 216, 27-46.

Kang, Y. H., Park, S. H., Lee, Y. J. Shin, H. K., Kang, J. S., Park, J. H. Y. and Bunger, R. (2002) Antioxidant ?-keto-carboxylate pyruvate protects low-density lipoprotein and atherogenic macrophages. Free Radic. Res. 36, 905-914.

Kashiwagi, A., Nishio, Y., Asahira, T., Ikebuchi, M., Harada, N., Tanaka, Y., Takagi, Y., Saeki, Y., Kikkawa, R. and Shigeta, Y. (1997) Pyruvate improves deleterious effects of high glucose on activation of pentose phosphate pathway and glutathione redox cycle in endothelial cells. Diabetes 46, 2088-2096.

Kehrer, J. P. and Lund, L. G. (1994) Cellular reducing equivalents and oxidative stress. Free Radic. Biol. Med. 17, 65-75.

Lowry, O. H., Rosebrough, N. J., Farr, A. L. and Randall, R. J. (1951) Protein measurement with the Folin phenol reagent. $J$. Biol. Chem. 193, 265-275.

Mallet, R. T. and Sun, J. (1999) Mitochondrial metabolism of pyruvate is required for its enhancement of cardiac function and energetics. Cardiovasc. Res. 42, 149-161. 
Martin, B. J., Lasley, R. D., Bunger, R. and Mentzer jr. R. M. (1998) Pyruvate augments calcium transients and cell shortening in rat ventricular myocytes. Am. J. Physiol. 274, H8-H17.

Mohazzab-H, K. M., Kaminski, P. M. and Wolin, M. S. (1997) Lactate and $\mathrm{PO}_{2}$ modulate superoxide anion production in bovine cardiac myocytes. Potential role of NADH oxidase. Circulation 96, 614-620.

Mongan, P. D., Fontana, J. L., Chen, R. and Bunger, R. (1999) Intravenous pyruvate prolongs survival during hemorrhagic shock in swine. Am. J. Physiol. 277, H2253-H2263.

Nishida, T., Shibata, H., Koseki, M., Nakao, K., Kawashima, Y., Yoshida, Y. and Tagawa, K. (1987) Peroxidative injury of the mitochondrial respiratory chain during reperfusion of hypothermic rat liver. Biochim. Biophys. Acta 890, 82-88.

Park, E. M., Park, J. S., Kim, Y. J., Sung J. S., Hwang, T. S., Kim, W. C., Han, M. Y. and Park, Y. M. (2001) Role of oxidative stress in the radiation-induced lung pathogenesis in mice. J. Biochem. Mol. Biol. 34, 544-550.

Ramakrishnan, N., Chen, R., McClain, D. E. and Bunger, R. (1998) Pyruvate prevents hydrogen peroxide-induced apoptosis. Free Radic. Res. 29, 283-295.
Rice-Evans, C. and Burdon, R. (1993) Free-radical lipid interactions and their pathological consequences. Prog. Lipid Res. 32, 71-110.

Scholz, T. D., Laughlin, M. R., Balaban, R. S., Kupriyanov, V. V. and Heineman, F. W. (1995) Effect of substrate on mitochondrial NADH, cytosolic redox state, and phosphorylated compounds in isolated hearts. Am. J. Physiol. 268, H82-H91.

Tejero-Taldo, M. I., Caffrey, J. L., Sun, J. and Mallet, R. T. (1999) Antioxidant properties of pyruvate mediate its potentiation of ?adrenergic inotropism in stunned myocardium. J. Mol. Cell. Cardiol. 31, 1863-1872.

Voogd, A., Slutier, W. and Kosrer, J. F. (1994) The increased susceptibility to hydrogen peroxide of the (post)-ischemic rat heart is associated with the magnitude of the low molecular weight iron pool. Free Radic. Biol. Med. 16, 453-458.

Yoon, S. J., Park, J. E., Yang, J. H. and Park, J. W. (2002) OxyR Regulon controls lipid peroxidation-mediated oxidative stress in Escherichia coli. J. Biochem. Mol. Biol. 35, 297-301.

Zhou, Z., Lasley, R. D., Hegge, J. O., Bunger, R. and Mentzer jr., R. M. (1995) Myocardial stunning: A therapeutic conundrum. J. Thoracic. Cardiovasc. Surg. 110, 1391-1401. 